\title{
Reminiscence: Evidence for reorganization in final free recall
}

\author{
OVID J. L. TZENG \\ University of California, Riverside, California 92502 \\ and \\ BARBARA A. HERGATT \\ Ohio State University, Columbus, Ohio 49210
}

\begin{abstract}
Sixty subjects learned four different 16-word lists in four different conditions. Within each list, every word was repeated. The four conditions were defined by a 2 (whole vs. blocked presentation) by 2 (same order vs. random order repetition) factorial design. An unexpected final free recall followed the immediate free recall of the fourth list. It was found that significantly more reminiscence occurred in the whole-random condition, suggesting that initially imposed organization hindered the subsequent reorganization.
\end{abstract}

Studies in the organization theory of memory (Mandler, 1967; Tulving, 1968) have so far focused on the organization within a single list. There are two basic experimental paradigms. One can look at the free recall protocols of a single categorized list, or one can examine the development of subjective organization in terms of the output consistency of recalled items in a multiple-trial free recall learning of a single list with unrelated words. The relationship between the measurement of organization and recall has been well documented (Tulving \& Donaldson, 1972). However, little attention has been paid to the problem of reorganization, even though its pedagogical implication is so obvious.

Ceraso (1967) asked his subjects to learn two different lists and observed that as time passed subjects' recall of the two lists tended increasingly to merge with each other, a process that he called "crowding." Ceraso (1967) employed this concept of "crowding" to explain the phenomenon of proactive inhibition and suggested a general theory of memory search. Such a search theory is in line with the modern version of organization theory with its emphasis on retrieval processes. If the learning of each single list requires the establishment of a retrieval plan, then "crowding" suggests a process of reorganization as a result of the interaction between the two lists. In this sense, the phenomenon of "crowding" demonstrates the dynamic nature of our memory system. This dynamic aspect of memory has rarely been studied within the realm of memory research.

Another essential aspect of an organization theory is the distinction between item availability and item

This research was supported by a special fund from the Dean of the College of Humanities and Social Sciences, University of California, Riverside, to the first author. Request for reprints should be sent to Ovid Tzeng, Department of Psychology, University of California, Riverside, California 92502. retrievability (Tulving \& Pearstone, 1966). Items may be available but not retrievable at the time of recall due to factors such as output interference, lack of appropriate retrieval cues, etc. If the process of "reorganization" actually underlies the phenomenon of "crowding," then one would expect to observe "reminiscence" in a study-test-test paradigm. With a multiple list and with Craik's (1970) modified study-recall-recall paradigm, one should be able to observe that some items which are not recalled in the immediate recall are recovered in the final recall because of the change in the retrieval plan resulting from the interactions among these different lists. There is evidence that reminiscence occurred in a study-recall-recall experiment (Tulving, 1967).

The present study presented further evidence to support the proposal that reminiscence could be regarded as a phenomenon resulting from the reorganization of stored items. Studies by Tzeng and Hung (1973) and by Tzeng, Snyder, and Hung (1972) revealed that intralist organization at the time of encoding could hinder reorganization in secondary memory. It was expected then, that reminiscence should be at a minimum in the situation where items were blocked during presentation.

\section{METHOD}

\section{Design and Materials}

The design was a 2 (blocked vs. whole presentation) by 2 (same vs. random repetition order) factorial design which yielded four experimental conditions with the following formats:

Condition 1: Block-Same

ABCDABCDEFGHEFGHIJKLIJKLMNOPMNOP

Condition 2: Block-Random

ABCDCADBEFGHHFGEIJKLJILKMNOPOPNM

Condition 3: Whole-Same

ABCDEFGHIJKLMNOPABCDEFGHIJKLMNOP

Condition 4: Whole-Random 
Table 1

Mean Number of Correct Recalls

\begin{tabular}{ccccc}
\hline & \multicolumn{2}{c}{ Block } & \multicolumn{2}{c}{ Whole } \\
& Same & Random & Same & Random \\
\hline IFR & 9.23 & 10.15 & 9.76 & 9.08 \\
FFR & 5.63 & 5.85 & 5.77 & 5.77 \\
\hline
\end{tabular}

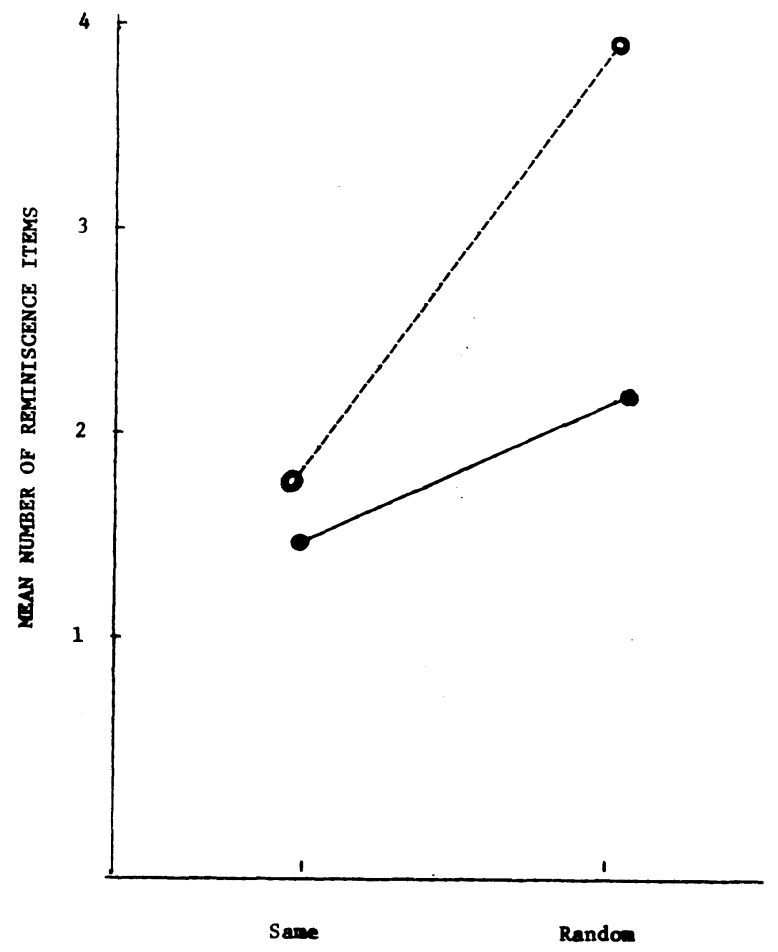

ORDER OF REPETITION

Figure 1. Mean number of reminiscence items as a function of presentation mode and repetition order.

The Symbols A. B. C. . . . P represented 16 unrelated words drawn randomiy from the word pool of common words.

\section{Procedure}

Every subject learned four different 16 -word lists. Within each list, every word was repeated according to the format defined by the subject's assigned condition. The items were presented one-by-one through a Kodak Carousel slide projector at a 3-sec rate. At the end of each list presentation, subjects were asked to free recall the 16 words in that list. Thus, there were four immediate free recall (IFR) tests for each subject. Upon the completion of the fourth list, subjects were asked for an unexpected final free recall (FFR), that is, they were to recall as many words as possible from all the previous lists. Five minutes were allowed for this FFR.

\section{Subjects}

Sixty high school seniors from the Galion High School in Galion, Ohio served as subjects. They participated in this experiment as a requirement for experimental credits for a psychology course. They were assigned to the four experimental conditions alternatively according to the order of their appearances at the laboratory.

\section{RESULTS}

The mean numbers of correct recall of both IFR and FFR for the four experimental conditions were summarized in Table 1. An inspection of Table 1 revealed that in terms of the mean numbers of correct recall, both IFR and FFR reflected little difference resulting from the two experimental manipulations. Analysis of variance for a 2 by 2 factorial design yielded not a single significant $F$ for both main effects nor for their interaction effect in IFR as well as in FFR.

Of particular interest in this study is the comparison among the total number of reminiscence items in the four experimental conditions. Figure 1 shows the mean numbers of reminiscence items in the four conditions.

The analysis of variance showed a significant main effect for presentation mode, with more reminiscence items being associated with the whole presentation conditions, $F(1,56)=13.19, p<.01$. The main effect of repetition order was also significant, with more reminiscence resulting from the random repetition, $F(1,56)=5.93, p<.05$. The interaction between these two experimental factors was not significant, $F(1,56)=2.03, \mathrm{p}<.05$.

\section{DISCUSSION}

The results of the present study both corroborate and extend the findings of Tulving (1967). He argued for the distinction between item availability and item retrievability by demonstrating the phenomenon of reminiscence in a single list free recall study where three outputs followed each input. The present study strengthens this argument by showing reminiscence in a multiple-list delayed recall situation.

The point of interest is that imposed organization during the encoding phase reduces the possibility of later reorganization and that randomizing the repetition order increases the probability of reorganization. Tzeng and his associates (Tzeng \& Hung, 1973; Tzeng et al., 1972) have suggested that any restriction on a subject's exposure to the whole list will have a detrimental effect on secondary memory. The results of the present experiment confirm this statement by showing that least reminiscence was observed in the block-same condition but highest reminiscence in the whole-random condition. It seems that the more restriction imposed at input, the harder it is for the subject to reorganize the items at a later time. In this sense, randomization of items at the second input may function as a "disorganization" process which relaxes the initial organization and makes the subsequent reorganization more probable.

Traditionally, forgetting has been conceptualized as loss of item information in memory. This, of course, imputes a negative function to forgetting. In an organization theory of memory emphasizing the retrieval aspect of our memory system, forgetting is not conceived as the degradation of memory trace. The present authors wish to suggest an alternative view of forgetting. Forgetting is not a phenomenon to be observed, instead, it is a process to be inferred from the initial organization of the to-be-learned material to its reorganization. Functionally, such a conceptualization assigns forgetting a positive value. Since reorganization unconditionally presupposes a dismantling of the initial organization, gaining new information would not be possible 
without the breaking down of some previous knowledge which up to that moment, had appeared to be final. In conclusion, one may say that whenever there is reorganization, there has been forgetting.

\section{REFERENCES}

Ceraso, J. The interference theory of forgetting. Scientific American, October, 1967, 117-124.

CraIK, F. I. M. The fate of primary memory items in free recall. Journal of Verbal Learning and Verbal Behavior, 1970, 9. 143-148.

MANDleR, G. Organization and memory. In K. W. Spence \& J. T. Spence (Eds.), The psychology of learning and motivation: Advances in research and theory (Vol. 1). New York: Academic Press, 1967. Pp. 327-372.

Tulving, E. The effects of presentation and recall of material in free-recall learning. Journal of Verbal Learning and Verbal Behavior, 1967, 6, 175-184.
Tulving, E. Theoretical issues in free recall. In T. R. Dixon \& D. L. Horton (Eds.), Verbal behavior and general behavior theory. Englewood Cliffs: Prentice-Hall, 1968. Pp. 2-36.

Tulving, E., \& Donaldson, W. Organization of memory. New York: Academic Press, 1972.

Tulving, E., \& Pearlstone, Z. Availability versus accessibility of information in memory for words. Journal of Verbal Learning and Verbal Behavior, 1966, 5, 381-391.

Tzeng, O. J. L., \& Hung, D. L. Intralist organization and subsequent free recalls. Journal of Experimental Psychology, 1973, 98, 119-124.

Tzeng, O. J. L., Snyder, H. I., \& Hung, D. L. The effects of overt intralist retrieval on subsequent free recalls. Psychonomic Science, 1972, 28, 103-105.

(Received for publication December 17, 1975.) 